\title{
Views of stakeholders on factors influencing shared decision-making in the Eastern Mediterranean Region: a systematic review
}

Nouf Alsulamy, ${ }^{1,2}$ Andrew Lee, ${ }^{1}$ Praveen Thokala ${ }^{1}$ and Tourkiah Alessa ${ }^{1,3}$

${ }^{1}$ School of Health and Related Research (ScHARR), University of Sheffield, Sheffield, United Kingdom. ${ }^{2}$ College of Business, University of Jeddah, Jeddah, Saudi Arabia. ${ }^{3}$ Biomedical Technology Department, College of Applied Medical Sciences, King Saud University, Riyadh, Saudi Arabia. (Correspondence to: Nouf Alsulamy: naalsulamyı@sheffield.ac.uk; n.alsulamy@gmail.com).

\begin{abstract}
Background: Shared decision-making is advocated as a key component of patient-centred care and associated with many benefits that improve patient outcomes. However, shared decision-making is not yet embedded in clinical practice and confronts many barriers that hinder its implementation especially in countries of the World Health Organization (WHO) Eastern Mediterranean Region.

Aims: We conducted a systematic review to identify and understand factors influencing shared decision-making in the Region.

Methods: We searched PsycINFO, CINAHL, PubMed, Medline, Scopus and Saudi Digital Library for articles published between January 1997 and February 2019. Studies conducted in the Region that reported barriers, facilitators, experiences, expectations and attitudes to shared decision-making were included. The Mixed Methods Appraisal Tool (MMAT) was used to assess the methodological quality of the studies in this review.

Results: Of the 1813 initial articles retrieved, 19 eligible articles were identified. The main factors that emerged were grouped under three broad themes: participant factors (patients/families and physicians); consultation factors (relationship between participants, engaging patients, evaluating preferences, introducing options, providing information, and decision making); and healthcare system factors (organizational characteristics, time constraints, continuity of care, and healthcare resources).

Conclusions: There is growing interest in shared decision-making in several countries in the Region. However, there are many existing barriers that hinder the implementation of shared decision-making. These need to be addressed before shared decision-making can be fully adopted in these countries.

Keywords: shared decision-making, Eastern Mediterranean Region, barriers, facilitators, implementation.

Citation: Alsulamy N; Lee A; Thokala P; Alessa T. Views of stakeholders on factors influencing shared decision-making in the Eastern Mediterranean Region: a systematic review. East Mediterr Health J. 2021;27(3):300-311 https://doi.org/10.26719/emhj.20.139

Received: 09/12/19; accepted: 05/04/20

Copyright (C) World Health Organization (WHO) 2021. Open Access. Some rights reserved. This work is available under the CC BY-NC-SA 3.0 IGO license (https://creativecommons.org/licenses/by-nc-sa/3.o/igo).
\end{abstract}

\section{Introduction}

Shared decision-making (SDM) is an approach in which physicians and patients work jointly, utilizing the best available evidence, to make decisions that considers the patients' preferences (1). SDM is considered to be a key component of patient-centred care and corroborated in high-level policy in developed countries $(2,3)$. Patients and clinicians in Western and non-Western countries show positive attitudes and preferences toward SDM (4-6). According to The Health Foundation (7), there is robust evidence of benefits from implementing SDM. These include greater treatment adherence, better patient confidence and coping skills, and reductions in the demand for major surgical interventions.

There is also a large and growing body of literature on the factors that influence SDM and its implementation, and many reviews have been conducted that provide comprehensive evidence on this topic (8-11). However, most of the reviews in the literature are from highincome settings, predominantly in Western countries. Little is known about SDM in the World Health
Organization (WHO) Eastern Mediterranean Region and it is not clear which factors may hinder or facilitate the implementation of it in these countries. Similarly, in many of the high-income Western countries, the concept of patient-centred care or SDM is being integrated into health systems, but this is not yet the case in the Region and other developing countries.

The Region comprises 21 countries as defined by WHO (12). Despite some cultural similarities (Islamic culture) and commonalities in historical background, there is also a high degree of diversity when it comes to developmental profiles and socioeconomic conditions that invariably affects the maturity of health systems and population health status in the different countries in the Region (13). Notably, the Region includes highmiddle-, lower- and lower-middle-income countries (14). Moreover, the culture, social context, and health sector leadership and governance in these countries are different to those in Western countries. If the desired aim is to promote and facilitate the integration of SDM into existing healthcare systems in the Region, there is a need to investigate and better understand the perception 
of SDM and challenges of implementing SDM in these countries. Therefore, we carried out a systematic review of the literature that sought to identify and understand the factors influencing SDM in the Region.

\section{Methods}

\section{Search strategy}

The following databases were searched for relevant articles published between 1997 and February 2019: PsycINFO, CINAHL, PubMed, Medline, Scopus, Saudi Digital Library, Open Grey, EThOS, Social Care Online. The search included other sources such as reference lists of included studies and articles citing the included studies. The searches were not restricted by language and relevant articles were translated into English. The search terms were built with help from one of the information specialists. We searched for articles on SDM or related concepts such as "patient engagement", "patient-centred care", "patient activation", "decision support" and "decision aids". Full details of the search strategies in (Medline, PsycINFO, CINAHL, Scopus and PubMed) can be found in Supplementary File 1. Other electronic databases were searched using keywords from the search strategies.

\section{Inclusion criteria}

The eligible studies were all qualitative, quantitative, or mixed-method studies that mentioned SDM or associated terms. Participants included were patients, families, healthcare and medical professionals, facility managers, and policy-makers. The intervention was SDM or its tools, such as decision aids, as they are tools often used in the SDM process. Studies were included if they reported perceptions, barriers, facilitators, experiences, expectations or attitudes to SDM. All healthcare settings in countries in the WHO Eastern Mediterranean Region were included.

\section{Study selection}

Electronic search results were exported to reference management software (Mendeley) and duplicated records were identified and excluded. Two reviewers (NA and TA) screened the titles and abstracts, and then full-text articles for exclusion or possible inclusion. Any uncertainty over inclusion of any article was resolved through discussion with researchers PT and AL and agreed by consensus.

\section{Data extraction and quality assessment}

One reviewer (NA) extracted data and assessed the quality of the included studies. The other reviewer (TA) verified the accuracy of the data extraction and quality assessment of all the included studies. Data were abstracted using a data extraction sheet developed specifically for this review. The variables extracted were: country of origin, healthcare setting, methodology and design of study, data collection tools, participants and sample size, aim of study, influencing factors, and type of results (Table 1). The Mixed Methods Appraisal Tool (MMAT) version 2018
(15) was used to assess the methodological quality of the studies. MMAT is a validated tool for appraising primary qualitative, quantitative and mixed-methods studies for systematic reviews. Although MMAT did not propose a scoring system, we categorized reviews as "good" when 6 or 7 of the criteria were achieved, "moderate" when 3-5 of the criteria were achieved, or "poor" when $0-2$ of the criteria were achieved.

\section{Data synthesis}

Narrative synthesis was used to synthesize the findings from multiple studies in the review, using words and text to summarize and explain the key findings (16). This approach was chosen due to the heterogeneity of study designs, study populations, types of factors, and study contexts. Study characteristics were extracted to describe the main features of each study (Table 1). The data extracted were compiled and key themes were subsequently identified and categorized.

\section{Ethical approval}

Ethical approval was not required.

\section{Results}

\section{Study selection}

The study selection process is summarized in the Preferred Reporting Items for Systematic Reviews and Meta-Analyses (PRISMA) flow diagram (Figure 1). The searches yielded 1813 references. After removing duplicates, there were 1201 unique articles, and 1172 were then excluded after screening by title and abstract. Of the remaining 29 full-text articles retrieved, 19 eligible articles were identified. The main reasons for exclusion included: studies did not mention SDM; focus on the purpose of the written informed consent; patients' views were on a specific decision, such as decision-making for antenatal screening, and not about the shared approach; or focus on how emergency physicians decide and assess the process of using clinical decision-making.

\section{Study characteristics}

An overview of the 19 included studies is presented in Table 1. They were from Islamic Republic of Iran, Saudi Arabia, Jordan, Oman, Morocco, Egypt and Pakistan. All were in English except for one in French (17).

Study participants included clinical staff (doctors and nurses), and patients and their family members. The study settings covered public, private and teaching hospitals, of which half were from teaching hospitals. Seven studies were from oncology units. The remaining studies were from other clinical settings: rehabilitation, neurology, dentistry, rheumatology, orthopaedics, anaesthesia, urology, gynaecology, emergency medicine, general internal medicine, and general surgery.

In terms of type of results, two studies assessed the role of family in the treatment decision-making process $(18,19)$. Seven studies reported patients' perspectives, participation, preferences, beliefs and knowledge $(4,5$, 


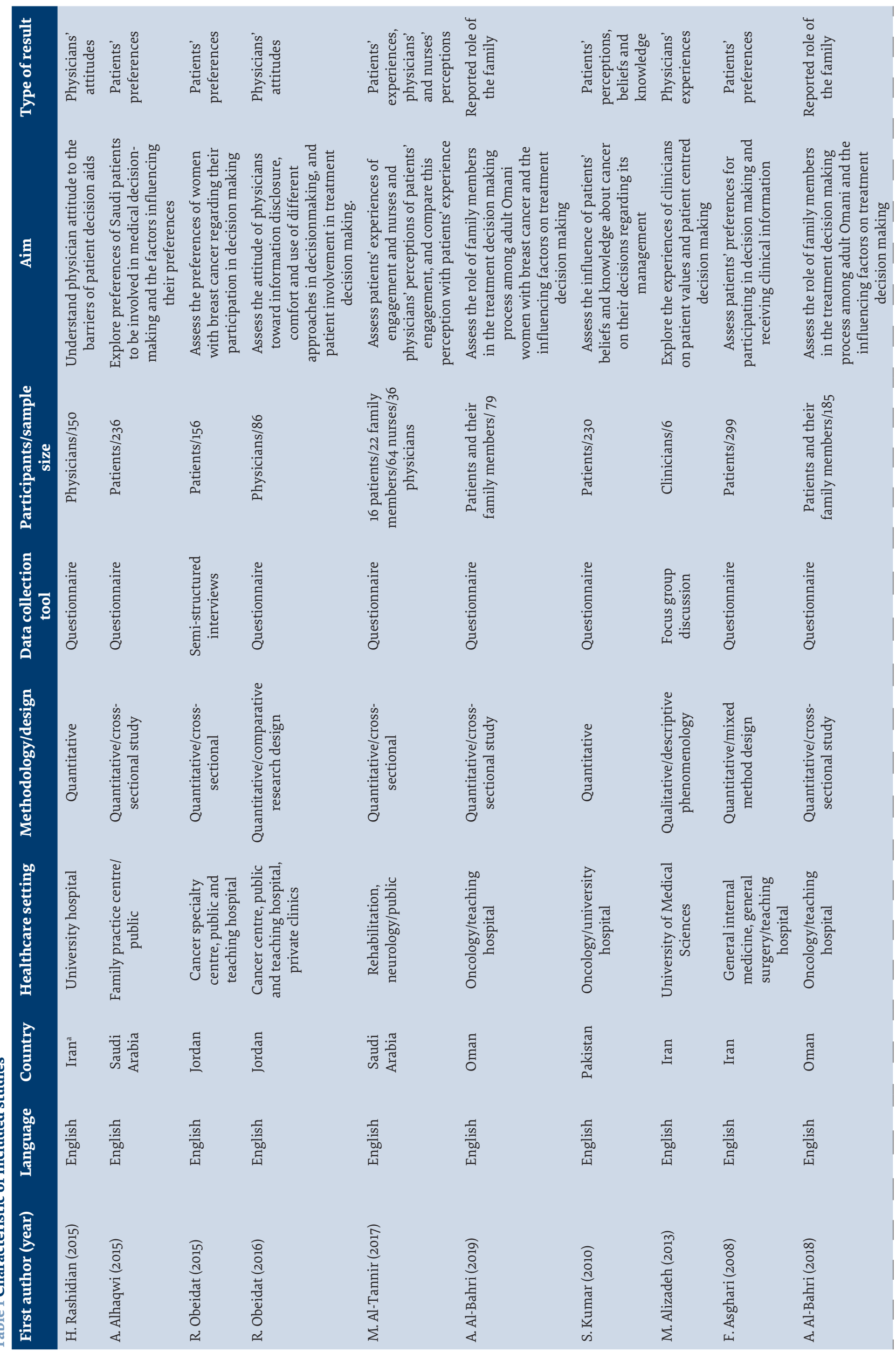




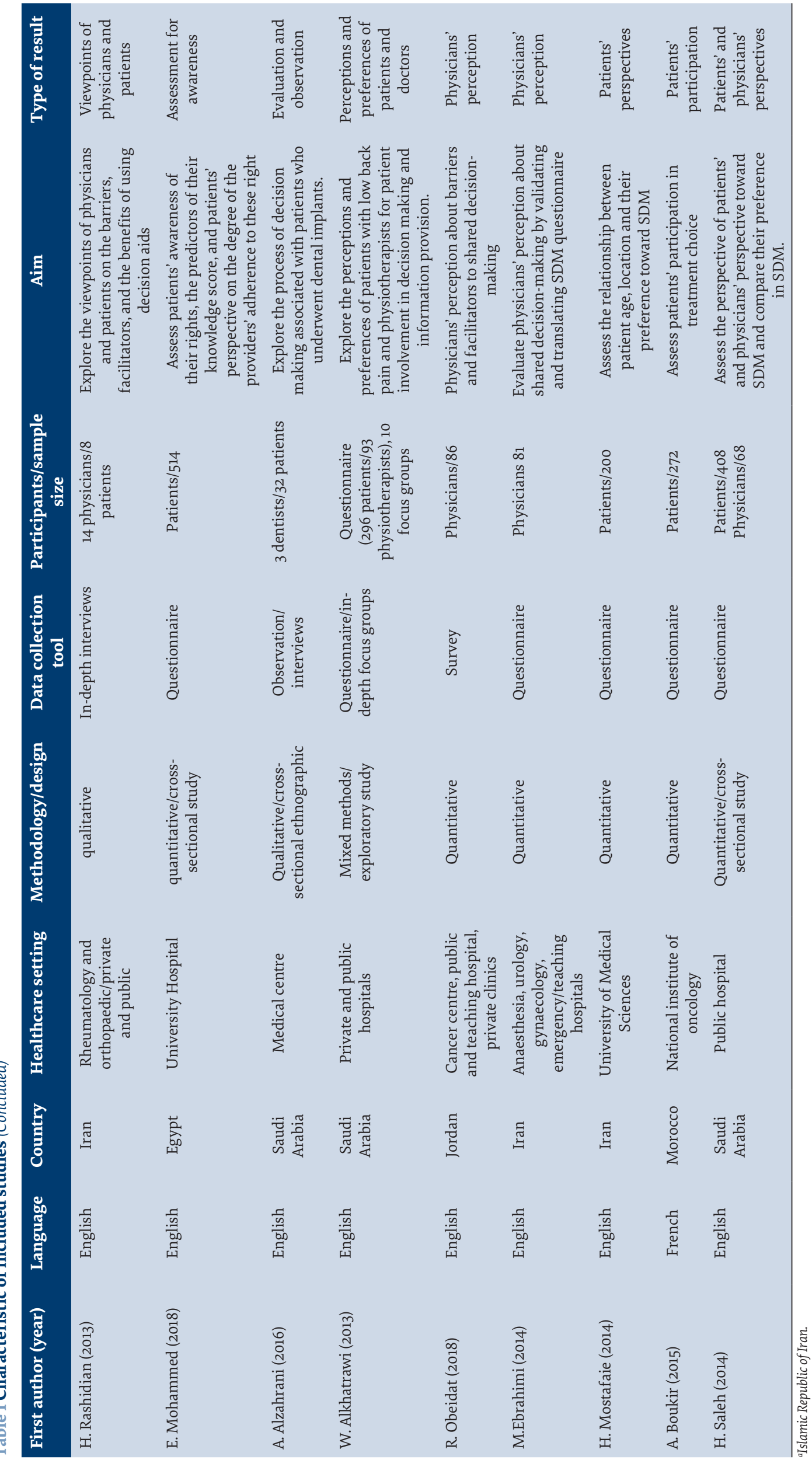




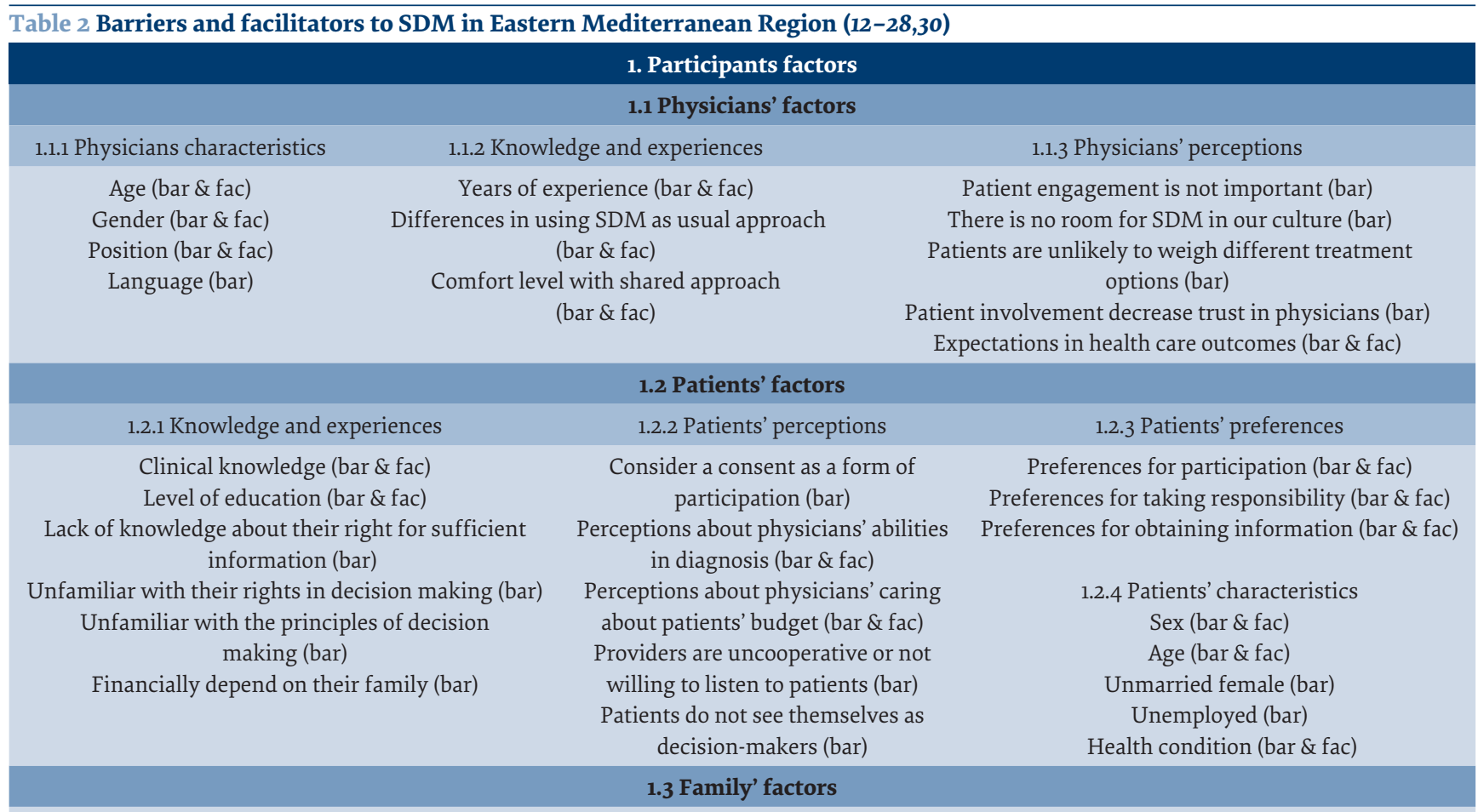

1.3.1 Degree of involvement

Accompany patients at the consultation (fac \& bar)

Over-riding the process of decision-making (bar)

\subsubsection{Families' attitudes}

Families' fears of patients' reaction to diagnosis (bar)

Families' beliefs in their responsibility for the treatment decision (bar)

Delays in informing their patients about the diagnosis (bar)

Families usually come together to discuss the decision and finalize it (bar)

\section{Consultation factors}

\subsection{Relationship between participants}

No effort to interact or build relationship with the patients (bar)

Respectful behaviour from physicians (bar \& fac)

Emotional support from physicians (bar \& fac)

Providing physical comfort for patients (fac)

Providing an opportunity to discuss Patients' problem (bar \& fac)

Passive role in communicating with providers during the visits (bar)

Providers and their roles are known by their patients (fac)

Cultural influences on the way of greeting and interaction (bar)

Trust in providers (bar \& fac)

$$
2.2 \text { Engaging patients }
$$

Degree to which physicians involve patients (bar \& fac)

Patients' satisfaction with the degree of being involved (bar \& fac)

Provider make patients feel they are partners (fac)

Consider patients' conditions (fac)

Initiating a discussion with patients about participating in decision making (fac)

Physicians clarify the necessity of making

\footnotetext{
a medical decision (fac)
}

\subsection{Evaluating preferences}

Considering patients' preferences (bar \& fac)

\subsection{Decision making}

Physicians select the final decision alone (bar)

Decision-making takes place in the presence or absence of the patient (bar)

Consider patients' rights to choose a treatment (fac)

Disagreement on treatment proceeding (bar)

Patients seek a second medical opinion abroad (bar)

Patients share the decision with more than 1 family member (bar)

Agreement between family members on the decision (bar)

Patients' emotional readiness for decisionmaking (fac)

Patients want their doctor to make the decision (bar)

Patient want their family to make the decision (bar)

\subsection{Introducing options}

Introducing options (bar \& fac) Physicians lead patients to use specific treatment (bar) Patients ask for a certain treatment (bar)

\subsection{Providing information}

Providing sufficient information for the treatment (bar \& fac) Help patients to understand all useful information (fac) 


\section{Table 2 Barriers and facilitators to SDM in Eastern Mediterranean Region $(\mathbf{1 2 - 2 8 , 3 0 )}$ (Concluded)}

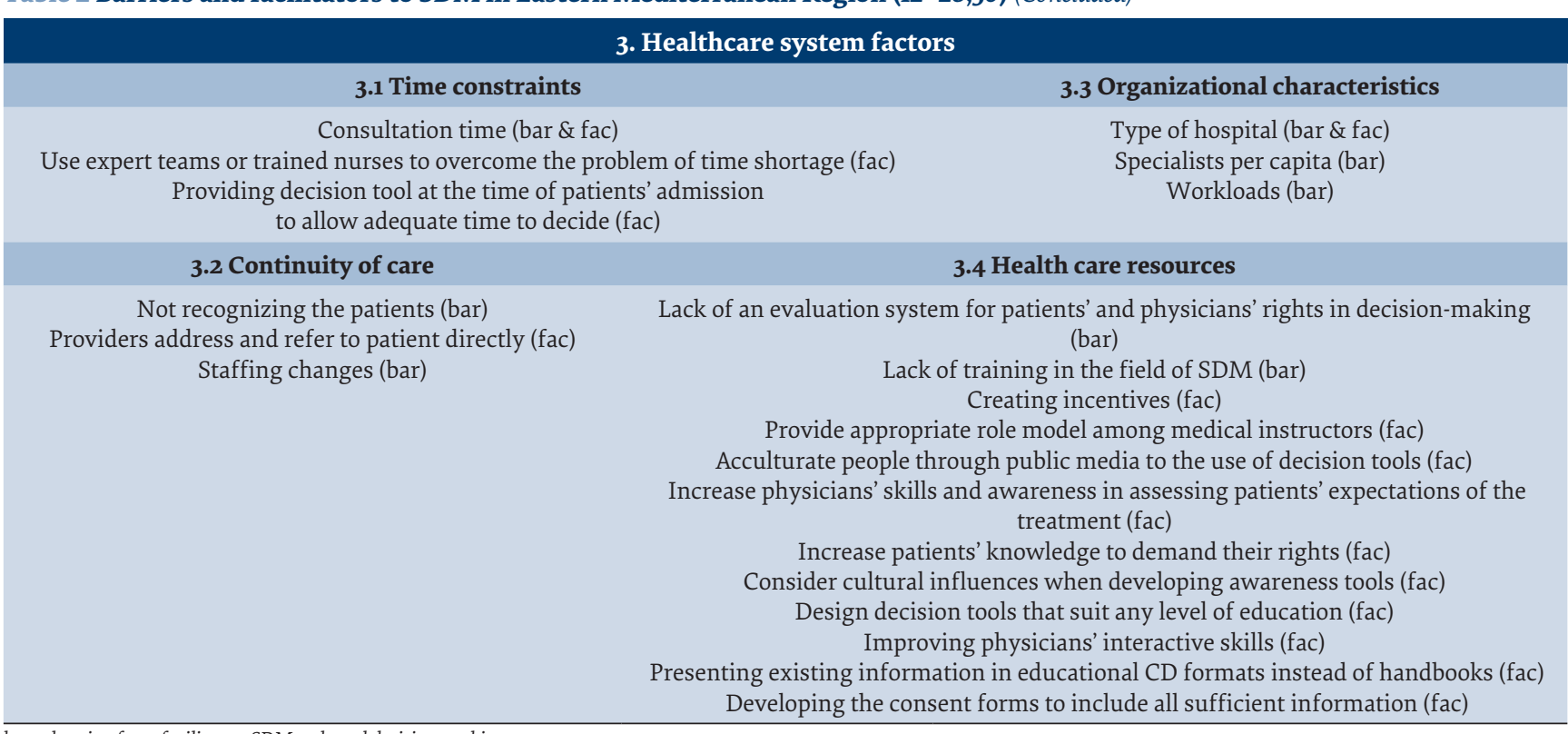

bar $=$ barrier $;$ fac $=$ facilitator $; D M=$ shared decision-making.

17,20-23). Five studies reported physicians' perceptions, attitudes and experiences (24-28). Four studies explored experiences, perceptions and preferences of both patients and clinical staff (29-33).

In terms of the aims of the studies, two sought to determine physicians' and patients' perspectives on barriers to and facilitators of the use of patient decision aids $(27,29)$. Two other studies assessed the role of family members in treatment decision-making and factors that influenced that decision $(18,19)$. The other studies reported on factors influencing physicians' and patients' preferences with regards to SDM. Only one study explored the process of decision-making by physicians and their patients during consultations (33).

Fifteen studies used a quantitative approach (mainly involving questionnaires). A qualitative approach was used in two studies $(26,29)$ and in one thesis $(33)$. A mixedmethods approach was used in another thesis (30).

\section{Quality assessment}

All of the included studies performed well in MMAT except for two that performed moderately $(31,32)$. The qualitative and mixed-methods studies met all of their criteria. However, the majority most of the quantitative studies were limited by use of convenience or purposive sampling techniques or small sample size (See Supplement 2).

\section{Barriers and facilitators}

The main themes were grouped under three broad themes: participant factors (factors related to patients or their families and physicians); consultation factors (factors related to the relationship between participants, patient engagement, evaluation of preferences, introduction of options, information provision, and decision-mak- ing); and healthcare system factors (factors related to organizational characteristics, time constraints, continuity of care, and healthcare resources). Subthemes were further grouped as either pertaining to patient, physician or family factors. Table 2 summarizes the identified barriers and facilitators under each theme.

Patients' age was reported to have an influence on SDM: 4 studies observed that older patients preferred a more passive role than younger patients $(4,18-20)$. Patients' sex was mentioned as a factor in 6 studies. Four of the included studies reported that male patients were more engaged than their female counterparts $(12,13,16$, 20), while 1 study confirmed the positive attitudes of women toward the shared approach (25). Another study reported the difficulty of engaging women because of their behaviour in comparing themselves with others and asking for the same treatment (15).

The patients' level of education was the most influential factor frequently reported in 10 studies as a barrier to or facilitator of patient participation in SDM $(4,17-20,23,27,29,30,32)$. Patients with higher levels of education were reported to have greater preference for SDM and willingness to participate. Conversely, patients with lower levels of education were said to trust their physicians for making decisions, and believed that their physicians knew best. The provision of sufficient information to patients was also reported in 4 different studies to be a facilitator for $\operatorname{SDM}(17,23,26,33)$.

The review also found that the family plays an important role in the decision-making process in the Eastern Mediterranean Region. Some of the included studies reported that family members engaged more than patients in SDM $(18,19,31)$. The family members' feelings of responsibility was cited as a reason for this. 
Figure 1 PRISMA diagram of barriers and facilitators to implementing shared decision-making in Eastern Mediterranean Region

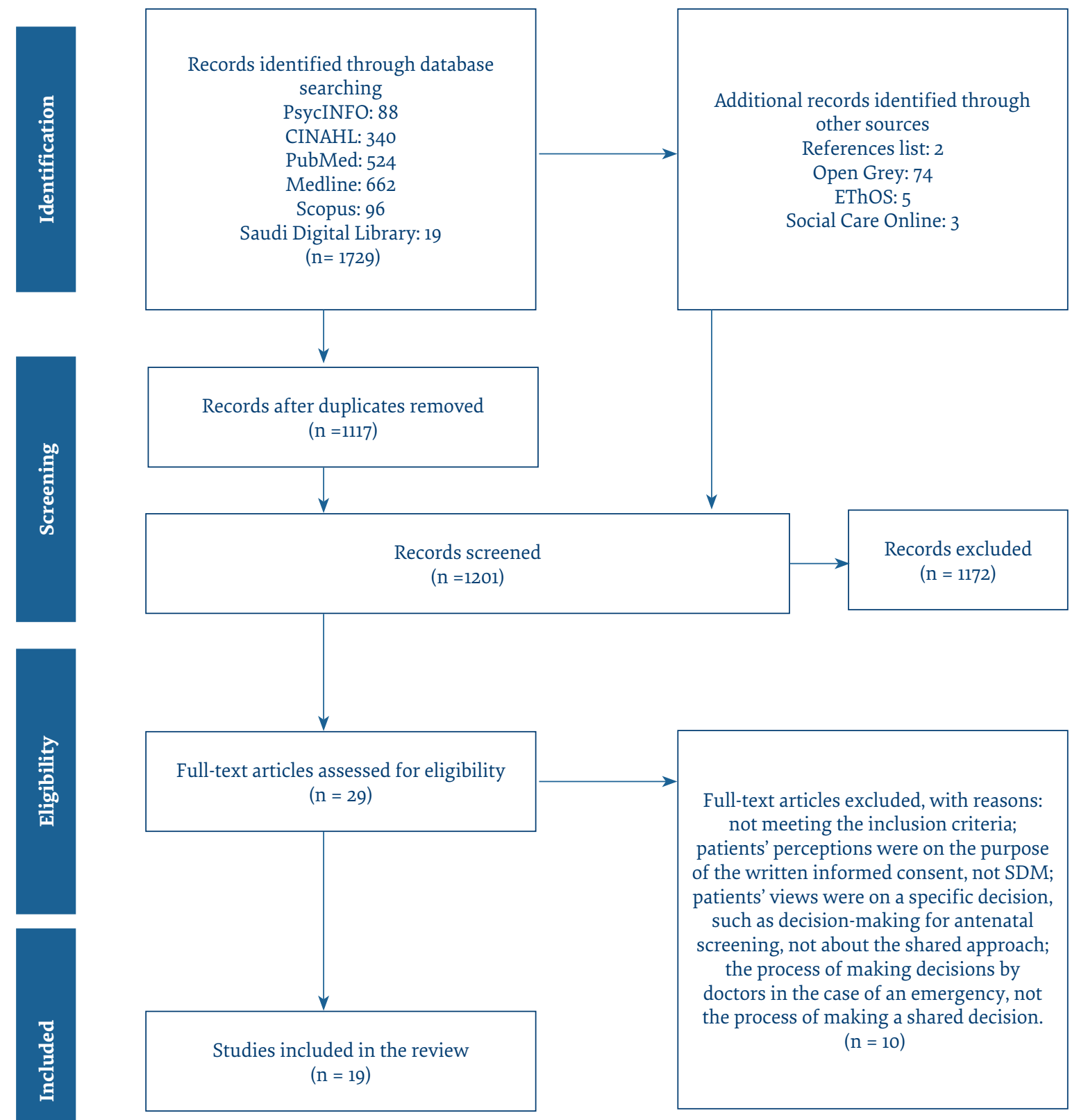

There were several healthcare system factors. Notably, time constraints and type of hospital were the most cited factors that influenced the adoption of $\operatorname{SDM}(25,29,30,32)$. Three studies found contrasting trends in the adoption of SDM by hospital type $(20,27,28)$. One study found that the shared approach was more likely to be used in a university hospital with a small caseload, while another study observed that it occurred in a private hospital. Another study reported that SDM was more likely to be used in speciality centres than in public, private or teaching hospital settings. However, it should be noted that these studies were only from Jordan.

\section{Discussion}

This review identifies several influential factors for SDM in the Eastern Mediterranean Region that include physician, patient and family member perspectives. These factors span the individual participant's role in decision -making, current SDM practices during clinical consultations, and SDM at the system level. However, the studies were from only seven countries. This indicates that SDM is not widely practised in countries in the Region as most developing countries have not integrated the concept of person-centred care into their health systems (34). 


\section{Participant factors}

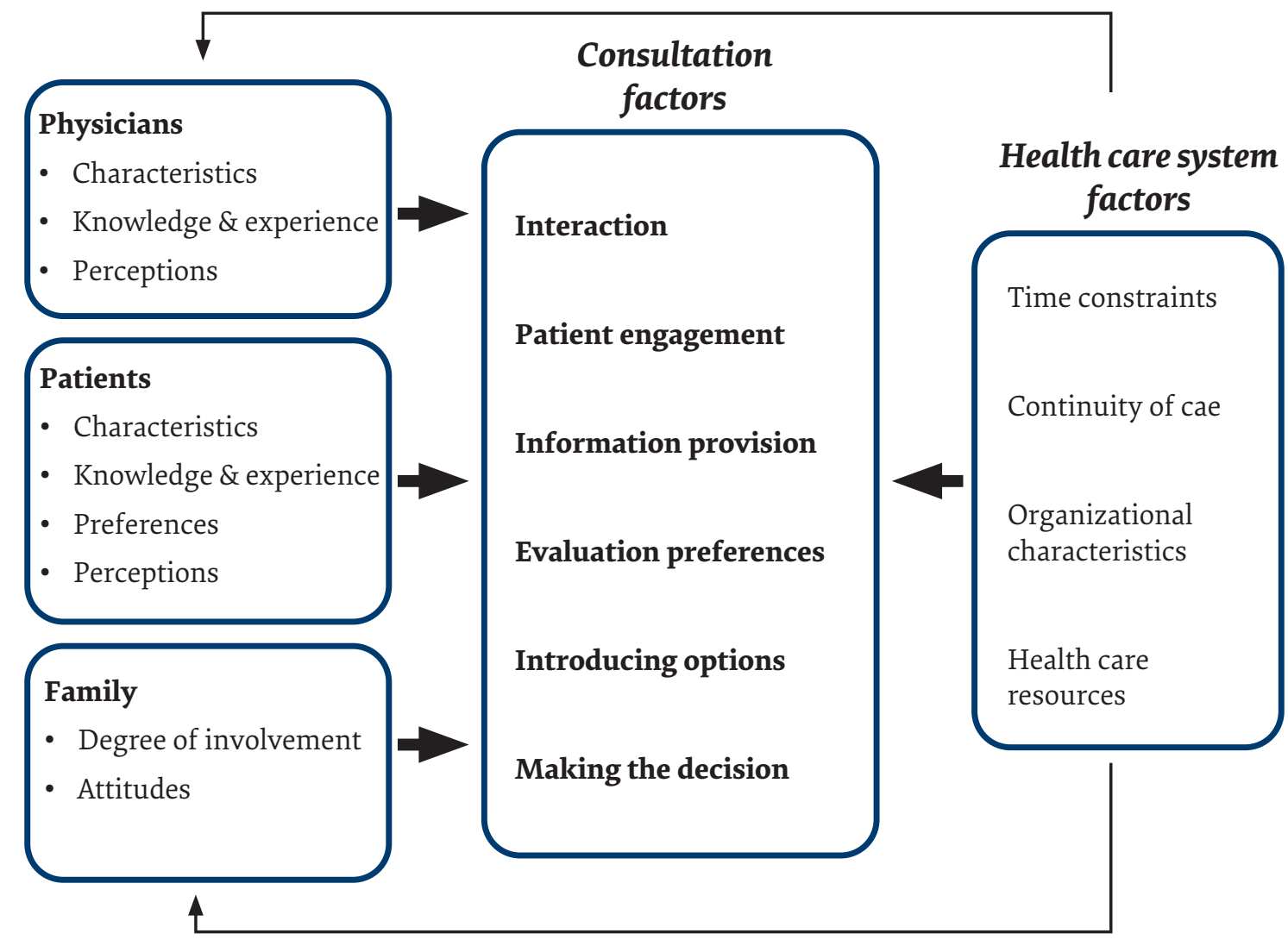

Unsurprisingly, patient and physician characteristics, such as their prior knowledge, experience and perceptions of SDM, and preferences towards it, are influential in determining whether it is practised. However, the practice of SDM is also affected by the attitudes of family members and the degree of their involvement in the decisions. These factors affect the interactions between the physicians and patients, as well as the consultation process including patient engagement, information provision and option sharing, elicitation and evaluation of patient preferences, and eventual decision-making. System-level factors also play a part such as time pressures, availability of healthcare resources to support SDM, and the degree of continuity of care provided. Figure 2 represents the relationship between these factors.

The most frequently cited factor was patients' level of education. Similar findings were previously reported in other studies from western countries $(35,36)$. Patients' age was also a determinant in the Region, with a notable preference for a passive role with increasing age. Although this mirrors a study from Japan (47), this age factor is not consistent worldwide. For example, one American study found that older people wanted to share their medical decisions or make their own (37). In the Region, older patients may lack clinical knowledge and have lower levels of education overall, which may explain the tendency towards adopting passive roles in decisionmaking (4,18-20).

This review found patient gender preferences for SDM. Al-Bahri and colleagues stated that family structures are more likely to be hierarchical in Middle Eastern culture (18). Traditionally, male family members such as husbands, fathers, and eldest sons have more authority in decision-making and therefore often dominate the decision-making process (38). This may explain the positive attitudes that male participants have towards decision-making. However, our review found that this trend was not universal and further exploration of the role of gender in decision-making is warranted, particularly as gender norms in the Region continue to evolve.

The quality of the physician-patient relationship is clearly vital and the behaviour of physicians is a key facilitator of patient trust (39). Linked to this is the adequacy of information provision as an enabler for SDM (40). Patient trust was boosted when physicians provided patients with a significant amount of information about their condition, test results, and adverse effects of different treatment options (39). However, patients' preferences for the amount of information provided differs among patients, and physicians need to tailor what information is exchanged with their patients. Key considerations include: the amount of prior knowledge 
that the patient has; how much information is considered to be sufficient; and who should decide if this information is enough for decision-making (41). An assessment of the level of patient understanding of the information provided is needed as there are variations in patients' health literacy.

Family involvement can facilitate patient participation in SDM and enhance this process. Family involvement can increase the probability for patients to experience positive emotions, and decrease the likelihood of them experiencing stress and uncertainty when making decisions about their condition (42). There are commonalities in the culture in the Region which has a collective nature and is family-centred. The families feel a moral responsibility for their members who are patients, and believe that they should be involved in the decisionmaking process $(43,44)$. That said, this is not unique to the Region and has been reported in other cultures where family involvement in the decision-making process enhances patients' engagement and autonomy (45). However, family involvement can also be a barrier to patient participation when the family dominates the decision-making process. Family involvement may disrupt communication between patients and physicians, and may delay treatment decisions where there are conflicting views (46). This raises the question of how best to include family members in the decision-making process.

A key limitation of this review is the diversity of the countries included in the Region, ranging from highincome countries like Saudi Arabia to more resource- constrained settings such as Pakistan. There are significant resource, socioeconomic and health system differences, as well as variations in demographic profiles. Moreover, the studies included did not cover all countries in the Region, and there were not many studies on SDM in the Region. Consequently, the aggregated findings in this review may not be truly representative or readily generalized to all countries in the Region. This highlights a need for further country-specific research into local SDM practices and determinants.

The implementation of SDM in any setting is subject to a complex landscape of interacting barriers. These need to be identified and addressed to ensure effective implementation, and can be enhanced through utilizing known facilitators. Much of the focus previously has been on physician factors, but as this review shows, there is a need to also address patient factors, family involvement, as well as wider health system issues. The development of simple patient decision aids that could be understood by patients with low literacy levels could be efficacious. Encouraging clinicians to provide patients with more tailored information is also key, but this will require resourcing such as the provision of more consultation time. We need more research that considers cultural norms and the organizational and health system perspective, as well as SDM research in other countries in the Region where little has been done so far. Future research into these aspects is warranted.

\section{Acknowledgement}

We thank all of those who contributed to this work. NA, the corresponding author, and TA would like to thank the Saudi Culture Bureau for sponsoring this project.

Funding: None.

Competing interests: None declared.

\section{Opinions des parties prenantes sur les facteurs influençant la prise de décision partagée dans la Région de la Méditerranée orientale : analyse systématique}

\section{Résumé}

Contexte : La prise de décision partagée est préconisée en tant que composante clé des soins centrés sur le patient et associée à de nombreux avantages qui améliorent les résultats pour ces derniers. Toutefois, ce mode de prise de décision n'est pas encore intégré dans la pratique clinique et se heurte à de nombreux obstacles qui entravent sa mise en œuvre, en particulier dans les pays de la Région de l'Organisation mondiale de la Santé (OMS) pour la Méditerranée orientale.

Objectifs : Réaliser une analyse systématique afin d'identifier et de comprendre les facteurs influençant la prise de décision partagée dans la Région.

Méthodes : Nous avons cherché des articles publiés de janvier 1997 à février 2019 dans PsycINFO, CINAHL, PubMed, Medline, Scopus et la bibliothèque numérique saoudienne. Les études menées dans la Région qui faisaient état des obstacles, des éléments favorisants, des expériences, des attentes et des attitudes vis-à-vis de la prise de décision partagée ont été incluses. L'outil d'évaluation des méthodes mixtes (MMAT) a été utilisé pour évaluer la qualité méthodologique des études de cette analyse. 
Résultats : Sur les 1813 articles initiaux récupérés, 19 articles éligibles ont été identifiés. Les principaux facteurs qui ont émergé ont été regroupés en trois grands thèmes : les facteurs associés aux participants (patients/familles et médecins) ; les facteurs de consultation (relation entre les participants, engagement des patients, évaluation des préférences, introduction des options, fourniture d'informations et prise de décision); et les facteurs liés au système de santé (caractéristiques organisationnelles, contraintes temporelles, continuité des soins et ressources sanitaires).

Conclusions : Plusieurs pays de la Région s'intéressent de plus en plus à la prise de décision partagée. Cependant, il existe de nombreux obstacles qui entravent la mise en œuvre de ce mode de prise de décision. Il faut s'attaquer à ces problèmes avant que la prise de décision partagée puisse être pleinement adoptée dans ces pays.

$$
\begin{aligned}
& \text { آراء أصحاب المصلحة المعنيين بشأن العوامل المؤثرة على عملية اتخاذ القرار المشترك في إقليم شرق المتوسط: } \\
& \text { استعر اض منهجي أرحاب } \\
& \text { نوف السلمي، أندرو لي، بر افين ثو كالا، تركيه العيسى }
\end{aligned}
$$

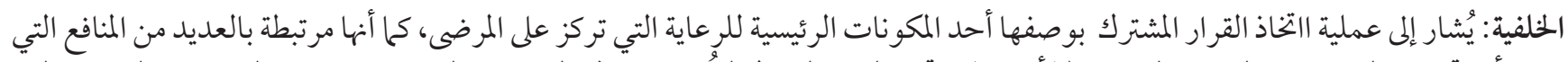

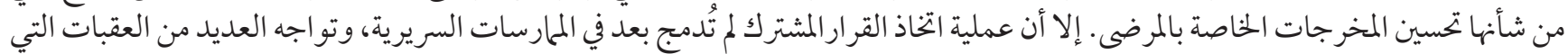
تحول دون تنفيذها، لا سيها في بلدان إقليم منظمة الصحة المخان العالمية لشرق المتوسط.

$$
\text { الأهداف: هدفت هذه الدراسة إلى استعر اض منهجي لتحديد العو امل المؤثرة على عملية اتخاذ القرار المشترك في الإقليم وفهمها. }
$$

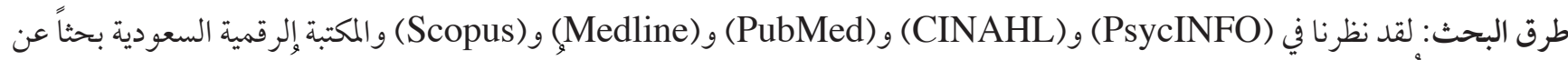

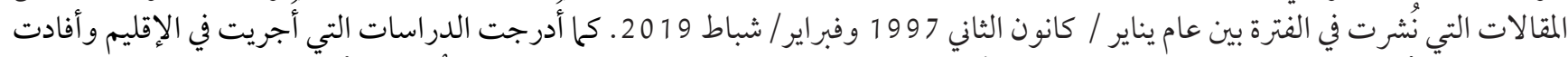

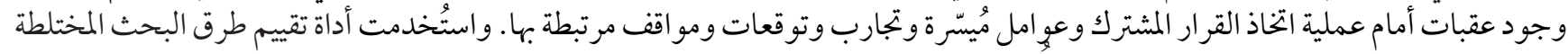
(MMAT)

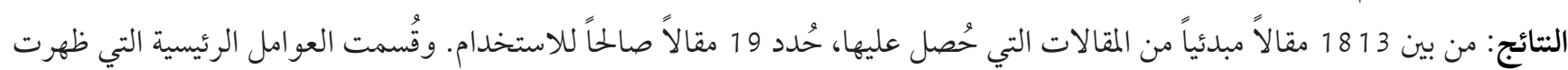

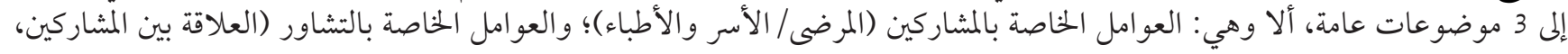

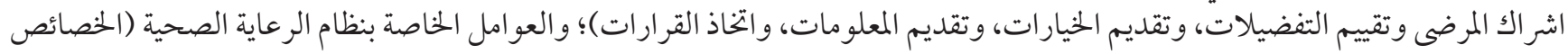

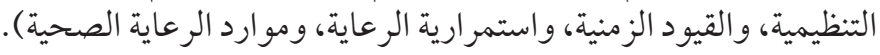

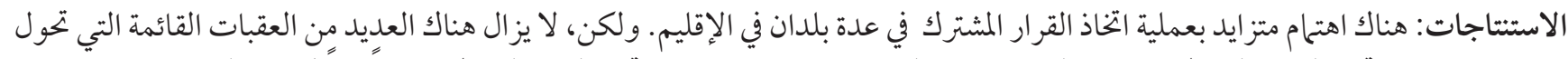

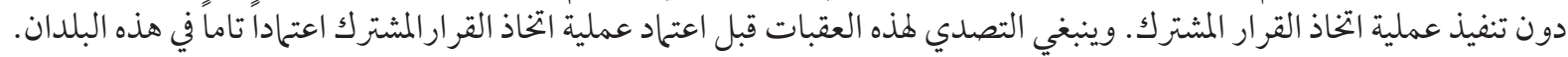

\section{References}

1. Elwyn G, Laitner S, Coulter A, Walker E, Watson P, Thomson R. Implementing shared decision making in the NHS. BMJ. 2010 Oct 14;341:c5146. http://dx.doi.org/10.1136/bmj.c5146 PMID: 2094757

2. NHS Constitution - interactive version [website]. 2009 (https://www.nhs.uk/NHSEngland/aboutnhs/Documents/NHS_Constitution_interactive_9Maro9.pdf, accessed 22 September 2020).

3. Adam J, Khaw F-M, Thomson R, Gregg P, Llewellyn-Thomas H. Patient decision aids in joint replacement surgery: A literature review and an opinion survey of consultant orthopaedic surgeons. Ann R Coll Surg Engl. 2008 Apr;90(3):198-207. http://dx.doi. org/10.1308/003588408X285748 PMID:18430333

4. AlHaqwi AI, AlDrees TM, AlRumayyan A, AlFarhan AI, Alotaibi SS, AlKhashan HI, et al. Shared clinical decision making. A Saudi Arabian perspective. Saudi Med J. 2015 Dec;36(12):1472-6. http://dx.doi.org/10.15537/smj.2015.12.13682 PMID:26620990

5. Asghari F, Mirzazadeh A, Fotouhi A. Patients' preferences for receiving clinical information and participating in decision-making in Iran. J Med Ethics. 2008 May 1;34(5):348-52. http://dx.doi.org/10.1136/jme.2007.021873 PMID:18448714

6. Harter M, Moumjid N, Cornuz J, Elwyn G, van der Weijden T. Shared decision making in 2017: International accomplishments in policy, research and implementation. Z Evid Fortbild Qual Gesundhwes. 2017 Jun;123-4. http://dx.doi.org/10.1016/j. zefq.2017.05.024 PMID:28546053

7. Summit report: leading the way to shared decision making. The critical steps for the NHS Commissioning Board to make "no decision about me, without me' a reality. The Health Foundation; 2012 (https://www.health.org.uk/publications/leading-the-wayto-shared-decision-making, accessed 22 September 2020).

8. Légaré F, Ratté S, Gravel K, Graham ID. Barriers and facilitators to implementing shared decision-making in clinical practice: update of a systematic review of health professionals' perceptions. Patient Educ Couns. 2008 Dec;73(3):526-35. http://dx.doi.org/ 10.1016/j.pec.2008.07.018 PMID:18752915 
9. Joseph-Williams N, Elwyn G, Edwards A. Knowledge is not power for patients: a systematic review and thematic synthesis of patient-reported barriers and facilitators to shared decision making. Patient Educ Couns. 2013 Mar;94(3):291-309. http://dx.doi. org/10.1016/j.pec.2013.10.031 PMID:24305642

10. Robertson EG, Wakefield CE, Signorelli C, Cohn RJ, Patenaude A, Foster C, et al. Strategies to facilitate shared decision-making about pediatric oncology clinical trial enrollment: a systematic review. Patient Educ Couns. 2018 Jul;101(7):1157-74. http://dx.doi. org/10.1016/j.pec.2018.02.001 PMID:29455939

11. Scholl I, LaRussa A, Hahlweg P, Kobrin S, Elwyn G. Organizational- and system-level characteristics that influence implementation of shared decision-making and strategies to address them - a scoping review. Implement Sci. 2018 Mar 9;13(1):40. http:// dx.doi.org/10.1186/s13012-018-0731-z PMID:29523167

12. About WHO. Regional Office for the Eastern Mediterranean [website]. Cairo: World Health Organization (https://www.who.int/ about/regions/emro/en/, accessed 22 September 2020).

13. Health systems in the Eastern Mediterranean Region: situation, challenges and gaps, priorities and WHO contribution. Cairo: World Health Organization Regional Office for the Eastern Mediterranean Region; 2012 (https://apps.who.int/iris/bitstream/ handle/10665/116086/High_Level_Exp_Meet_Rep_2012_EN_14496.pdf?sequence=1, accessed 22 September 2020).

14. Report on primary health care in the Eastern Mediterranean Region: review of progress over the last decade (2008-2018). Cairo: World Health Organization Regional Office for the Eastern Mediterranean Region; 2018 (https://www.who.int/docs/default-source/primary-health-care-conference/phc-regional-report-eastern-mediterranean.pdf?sfvrsn=2a5a2528_2, accessed 22 September 2020).

15. Hong QN, Pluye P, Fàbregues S, Bartlett G, Boardman F, Cargo M, et al. Mixed methods appraisal tool (MMAT), version 2018. User guide. [website] Montreal: Department of Family Medicine, McGill University; 2018 (http://mixedmethodsappraisaltoolpublic.pbworks.com/w/file/fetch/127425851/MMAT_2018_criteria-manual_2018-04-04.pdf, accessed 22 September 2020).

16. Popay J, Roberts H, Sowden A, Petticrew M, Arai L, Rodgers M, et al. Guidance on the conduct of narrative synthesis in systematic reviews: a product from the ESRC Methods Programme. 2006 (https://www.lancaster.ac.uk/media/lancaster-university/ content-assets/documents/fhm/dhr/chir/NSsynthesisguidanceVersion1-April2006.pdf, accessed 22 September 2020).

17. Boukir A, Azghari I, El Kabous M, Jouid K, Boutayeb S, El Ghissassi I, et al. Moroccan patient participation with cancer to therapeutic choice: results of a survey of 272 patients. Pan Afr Med J. 2015 Oct 22;22:174 (in French). http://dx.doi.org/10.11604/ pamj.2015.22.174.7040 PMID:26918070

18. Al-Bahri A, Al-Moundhri M, Al-Mandhari Z, Al-Azri M. The role of patients' families in treatment decision-making among adult cancer patients in the Sultanate of Oman. Eur J Cancer Care (Engl). 2018 May;27(3):e12845. http://dx.doi.org/10.1111/ecc.12845. PMID:29667246

19. Al-Bahri A, Al-Moundhri M, Al-Mandhari Z, Al-Azri M. Role of the family in treatment decision-making process for Omani women diagnosed with breast cancer. Patient Educ Couns. 2019 Feb;102(2):352-9. http://dx.doi.org/10.1016/j.pec.2018.08.026 PMID:30170824

20. Obeidat R. Decision-making preferences of Jordanian women diagnosed with breast cancer. Support Care Cancer. 2015 Aug;23(8):2281-5. http://dx.doi.org/10.1007/s00520-014-2594-4 PMID:25576431

21. Kumar S, Shaikh AJ, Khalid S, Masood N. Influence of patient's perceptions, beliefs and knowledge about cancer on treatment decision making in Pakistan. Asian Pac J Cancer Prev. 2010;11(1):251-5. PMID:20593966

22. Mohammed E, Seedhom A, Ghazawy E. Awareness and practice of patient rights from a patient perspective: an insight from Upper Egypt. Int J Qual Heal Care. 2018 Mar;30(2):145-51. https://doi.org/10.1093/intqhc/mzx182

23. Mostafaie H. Shared decision-making and its correlation with demographic characteristics of Iranian patients. Br J Med Med Res. 2014;4(16):3140-7. https://doi.org/10.9734/BJMMR/2014/8841

24. Ebrahimi M. Physicians' perspectives toward shared decision making in developing countries. Br J Med Med Res. 2014;4(18):3458-64. https://doi.org/10.9734/BJMMR/2014/8839

25. Obeidat RF, Lally RM. Jordanian physicians' perceived barriers and facilitators to patient participation in treatment decision-making: an exploratory study. Indian J Cancer. 2018 Oct-Dec;55(4):514-8. http://dx.doi.org/10.4103/ijc.IJC_122_18 PMID:30829274

26. Alizadeh M, Tabrizi J, Kia N, Khanlarzadeh E, Khamnian Z. A qualitative study on the experiences of specialists on patient-oriented decision making in a developing country. Res Dev Med Educ. 2013 Jun;2(2):83-6. http://dx.doi.org/10.5681/rdme.2013.019

27. Rashidian H, Nedjat S, Mounesan L, Haghjou L, Majdzadeh R. The attitude of physicians toward the use of patient decision aids in Iran as a developing country. Int J Prev Med. 2015 Feb 20;6:18. http://dx.doi.org/10.4103/2008-7802.151827 PMID:25789150

28. Obeidat R, Khrais HI. Jordanian physicians' attitudes toward disclosure of cancer information and patient participation in treatment decision-making. Asia-Pacific J Oncol Nurs [Internet]. 2016 Jul-Sep;3(3):281-8. http://dx.doi.org/10.4103/2347-5625.189811 PMID:27981172

29. Rashidian H, Nedjat S, Majdzadeh R, Gholami J, Haghjou L, Abdollahi BS, et al. The perspectives of Iranian physicians and patients towards patient decision aids: a qualitative study. BMC Res Notes. 2013 Sep 25;6:379. http://dx.doi.org/10.1186/1756-05006-379 PMID:24066792

30. AlKhatrawi W. An exploratory study of patients' and physiotherapists' perceptions and preferences when making decisions and sharing information about managing low back pain in Saudi Arabia [thesis]. King's College London; 2013. 
31. Al-Tannir M, AlGahtani F, Abu-Shaheen A, Al-Tannir S, AlFayyad I. Patient experiences of engagement with care plans and healthcare professionals' perceptions of that engagement. BMC Health Serv Res. 2017 Dec;17(1):853. https://doi.org/10.1186/s12913017-2806-y

32. Saleh HA, Ramadan R, Ghazzawi G, Kalantan N, Mounshi B, Fatani K, et al. Patient Shared Decision Making: Physicians' and Patients' Perspective. Int J Pure Appl Sci Technol. 2014 Jun;22(2):10-7.

33. Alzahrani AAH. Decision making and dental implant treatments in Saudi Arabia [thesis]. University of Sheffield; 2016.

34. Qidwai W, Nanji K, Khoja T, Rawaf S, Al Kurashi NY, Alnasir F, et al. Are we ready for a person-centered care model for patient-physician consultation? A survey from family physicians of East Mediterranean Region. Eur J Pers Centered Healthc. 2016;1(2):394. https://ecommons.aku.edu/pakistan_fhs_mc_fam_med/48

35. Adams RJ, Smith BJ, Ruffin RE. Patient preferences for autonomy in decision making in asthma management. Thorax. 2001 Feb;56(2):126-32. http://dx.doi.org/10.1136/thorax.56.2.126 PMID:11209101

36. Mazur DJ, Hickam DH. Patients' preferences for risk disclosure and role in decision making for invasive medical procedures. J Gen Intern Med. 1997 Feb;12(2):114-7. http://dx.doi.org/10.1046/j.1525-1497.1997.00016.x PMID:9051561

37. Chiu C, Feuz MA, McMahan RD, Miao Y, Sudore RL. "Doctor, make my decisions": Decision control preferences, advance care planning, and satisfaction with communication among diverse older adults. J Pain Symptom Manage. 2016;51(1):33-40. http:// dx.doi.org 10.1016/j.jpainsymman.2015.07.018 PMID:26342727

38. Valentine M. Patriarchy in transition: women and the changing family in the Middle East. J Comp Fam Stud. 2004;35(2):137-63. https://psycnet.apa.org/record/2004-11038-001

39. Peek ME, Gorawara-bhat R, Quinn MT, Odoms-young A, Chin MH. Patient trust in physicians and shared decision-making among African-Americans with diabetes. Health Commun. 2013;28(6):616-23. http://dx.doi.org/10.1080/10410236.2012.710873 PMID:23050731

40. Dy SM, Purnell TS. Key concepts relevant to quality of complex and shared decision-making in health care: a literature review. Soc Sci Med. 2012 Feb;74(4):582-7. http://dx.doi.org/10.1016/j.socscimed.2011.11.015 PMID:22236643

41. Feldman-Stewart D, Madarnas Y, Mates M, Tong C, Grunfeld E, Verma S, et al. Information for decision making by post-menopausal women with hormone receptor positive early-stage breast cancer considering adjuvant endocrine therapy. Breast. 2013 Oct;22(5):919-25. http://dx.doi.org/10.1016/j.breast.2013.04.020 PMID:23721853

42. Kitayama S, Park H, Sevincer AT, Karasawa M, Uskul AK. A cultural task analysis of implicit independence: comparing North America, Western Europe, and East Asia. J Pers Soc Psychol. 2009 Aug;97(2):236-55. http://dx.doi.org/10.1037/a0015999 PMID:19634973

43. Shin DW, Cho J, Roter DL, Kim SY, Sohn SK, Yoon MS, et al. Preferences for and experiences of family involvement in cancer treatment decision-making: patient-caregiver dyads study. Psychooncology. 2013 Nov;22(11):2624-31. http://dx.doi.org/10.1002/ pon.3339 PMID:23893390

44. Bian L. Medical individualism or medical familism? A critical analysis of China's new guidelines for informed consent: the basic norms of the documentation of the medical record. J Med Philos. 2015 Aug;40(4):371-86. http://dx.doi.org/10.1093/jmp/jhvo16 PMID:26070661

45. Laidsaar-Powell R, Butow P, Bu S, Charles C, Gafni A, Fisher G. Family involvement in cancer treatment decision-making: a qualitative study of patient, family, and clinician attitudes and experiences. Patient Educ Couns. 2016 Jul;99(7):1146-55. http://dx.doi. org/10.1016/j.pec.2016.01.014 PMID:26873544

46. Burney IA. The trend to seek a second opinion abroad amongst cancer patients in Oman: challenges and opportunities. Sultan Qaboos Univ Med J. 2009 Dec;9(3):260-3. PMID:21509308

47. Nomura K, Ohno M, Fujinuma Y, Ishikawa H. Patient autonomy preferences among hypertensive outpatients in a primary care setting in Japan. Intern Med. 2007;46(17):1403-8. http://dx.doi.org/10.2169/internalmedicine.46.0141 PMID:17827839 